\title{
COMPARAÇÃO DA CAPACIDADE OVIPOSITORA DE BIOMPHALARIA GLABRATA (SAY, 1818), BIOMPHALARIA TENAGOPHILA(D'ORBIGNI, 1835) E BIOMPHALARIA STRAMINEA (DUNKER, 1848), MANTIDAS EM LABORATORIO.*
}

\author{
Odair Genaro * *
}

\begin{abstract}
O autor comparou a capacidade ovipositora de 3 espdcies de Planorbidae, Biomphalaria glabrata, B. tenagophila $\theta$ B. straminea durante um período de 30 dias, compreandidos entre os meses de Março $\theta$ Abril de 1978. Registrou-se diariamente o número de ovos e desoves, referentes a 20 exemplares de ceda espécie em questío. A andlise estatística dos dedos obtidos revelou que os exemplares de B. glabrata apresentaram maior capacidade ovipositora que as outras duas espócies em questio. A menor capacidade ovipositora foi atribuida à espécie B. tenagophila.
\end{abstract}

\section{INTRODUÇÃO}

Segundo Coelho ${ }^{3}$ a esquistossomose mansônica apresenta larga distribuição geográfica, abrangendo extensas regiões do território nacional, sendo observada numa faixa contínua que se estende sobretudo, das localidades litorâneas e da Zona da Mata do Estado do Rio Grande do Norte, até a região central de Minas Gerais. Focos isolados existem no Estado do Pará (Fordlândia e Quatipurú) e no Estado do Maranhão (Cururupu e São Bento). No Estado do Ceará a doença é endêmica em Redenção e Pacotí; outros focos ainda são encontrados em Quixadá, Juazeiro do Norte, Morada Nova e Limoeiro do Norte. Ainda segundo Coelho ${ }^{3}$, os principais focos estão localizados no nordeste do País, como por exemplo, na área central do Estado de Sergipe, onde o Indice de positividade desta parasitose chegou a $86,57 \%$, segundo inquérito realizado por Pellon \& Teixeira em $1953^{10}$. No sul e centro do Brasil săo conhecidos focos nos Estados do Espírito Santo, Rio de Janeiro, São Paulo, Paraná, Goiás e em Brasília.

No norte do Estado do Paraná, registrava-se baixa pfevalência para esta parasitose até alguns anos atrás, apesar de vários focos serem conhecidos. O primeiro foco foi descrito no município de Jacarezinho, por Coutinho \& Pessôa em 19494. Mais tarde outros foram assinalados em Uraí, Jataízinho, Santo Antonio da Platina, Monte Real e Maticanã por Ribeiro \& cols. ${ }^{16}$; Rey \& cols. ${ }^{13}$ e Lobo \& cols. ${ }^{8}$.

Três décadas após a descoberta do primeiro foco, a esquistossomose vem se dispersando de tal modo nesta região, que em futuro muito próximo, caso medidas profiláticas urgentes não forem tomadas, o norte do Paraná poderá se constituir em importante zona endêmica.

Como se sabe, as três principais espécies de moluscos vetores no Brasil são: Biomphalaria glabrata, Biomphalaria tenagophila e Biomphalaria straminea. No Estado do Paraná é ampla a distribuição das espécies $B$. glabrata e $B$. tenagophila. Lima? . Esta última tem se mostrado resistente à infecção experimental por cêpa simpátrica e alopátrica (originária de Belo Horizonte, MG) de Schistosoma mansoni Chieffi ${ }^{1}$. Portanto, ao que tudo indica, o único molusco responsável pela manutenção e dispersão da esquistossomose no Estado do Paraná, é a espécie B. glabrata.

Reconhecendo então a importância epidemiológica entre as duas espécies vetoras autóc-

\footnotetext{
- Realizado no Departamento de Patologia Geral, Centro de Ciencias Biológicas de Universidade Estadual de Londrina-PR, com auxílio do Projeto Bolsa-Trabalho/Pesquisa-FUEL/MEC.DAE.

* Universidade Estadual de Londrina.
} 
tones, propusemo-nos estudar um de seus aspectos biológicos que se reveste de fundamental importância: a capacidade de oviposição.

\section{MATERIAL E MÉTODOS}

O método utilizado foi semelhante ao adotado por Kawazoe ${ }^{6}$. Foram utilizados 20 exemplares de cada espécie, e distribuídos 2 moluscos da mesma espécie em cada cristalizador, com capacidade para $800 \mathrm{ml}$ de água.

No presente trabalho utilizamos caramujos criados em laboratório. As espécies B. glabrata e B.tenagophila eram descendentes de exemplares originários do município de Londrina-PR e os de $B$. straminea provenientes de canais de irrigação construidos pelo Departamento Nacional de Obras Contra Sêcas (DNOCS), em área situada entre Morada Nova e Limoiro do Norte-CE. Foram utilizados indivíduos adultos cujo diâmetro variou de 15 a $17 \mathrm{~mm}$ para $B$. glabrata, 12 a $14 \mathrm{~mm}$ para $B$. tenagophila e 5 a $7 \mathrm{~mm}$ para $B$. straminea. A medida que morriam, eram imediatamente substituídos por outros de igual tamanho.

A água dos cristalizadores era desprovida de cloro (oriunda de poço artesianol e renovada a cada 2 dias. A alimentação fornecida foi sempre alface fresca e ração especial para peixes (Vitormônio). No decorrer de 1 mês de observação, foram registrados diariamente o número de desovas. As oviposições em sua maioria, foram depositadas na parede do frasco. As efetuadas sobre as conchas dos moluscos e sobre as folhas de alface, foram isoladamente transferidas para um becker onde eram contadas.

\section{RESULTADOS}

Os exemplares de B. glabrata produziram 493 cápsulas ovígeras, perfazendo um total de 16.314 ovos. No caso de B. tenagophila, produziram 180 cápsulas ovígeras com um total de $\mathbf{2} .049$ ovos. Já os 20 exemplares da espécie B. straminea produziram 481 cápsulas ovígeras com um total de 6.611 ovos.

No quadro I e figura I e 11 , os resultados obtidos estão melhor expressos.

Para a interpretação da diferença do número médio de ovos por desova nas 3 espécies estudadas, foi utilizado o teste de KRUSKAL-WALLIS.

A média da temperatura ambiente minima foi de $23,15^{\circ} \mathrm{C}$ e a média da temperatura máxima foi de $30,1^{\circ} \mathrm{C}$, sendo que a média da temperatura da água foi de $24,48^{\circ} \mathrm{C}$. A temperatura ambiente mais baixa registrada durante o experimento foi de $19^{\circ} \mathrm{C}$ e a mais alta de $33^{\circ} \mathrm{C}$.

\section{DISCUSSÃo}

Em alguns dos trabalhos realizados (Quadro (I), observamos que o diâmetro dos moluscos utilizados, está de certo modo, relacionado com sua capacidade de oviposição. Este fato, aliado aos diferentes métodos empregados pelos autores e ainda às variações sazonais em que ocorreram, contribuiu para a obtenção de resultados diferentes. Os resultados encontrados por Chieffi \& cols. ${ }^{2}$, nas espécies $B$. glabrata e B. tenagophila (Quadro II), mostram-nos que o número de ovos por desova, foi ligeiramente superior para B. tenagophila; contudo, quando o autor comparou o número de ovos produzidos diáriamente por caramujo, verificou que $B$. glabrata apresentou nítida vantagem.

No presente trabalho utilizamos estas mesmas populações de $B$. glabrata e $B$. tenagophila. Nossos resultados diferem dos obtidos por Chieffi \& cols., uma vez que, o número médio de ovos por desova por nós observado foi de 33,09 para $B$. glabrata e 11,38 para $B$. tenagophila, superior e inferior respectivamente aos números daqueles autores. Esta comparação entre resultados merece uma ressalva, uma vez que Chieffi \& cols não citam o diâmetro dos moluscos por eles utilizados. Este tipo de divergência de dados, também foi notado por Rey ${ }^{14}$ quando encontrou médias variando de 9,4 a 22,7 ovos por desova numa mesma população de $B$. glabrata e 9,7 a 24,7 em uma única população de $B$. tenagophila.

Ao nível de significância de $5 \%$, o teste de KRUSKAL WALLIS revelou diferença alta. mente significativa no número de ovos por desova entre as espécies $B$. glabrata e $B$. tenagophila. A análise entre $B$. glabrata e $B$. straminea também mostrou diferença significativamente maior para $B$. glabrata. Entre as espécies $B$. tenagophila e $B$. straminea a diferença obse vada no número de ovos por desova "ĩn in significativa.

Quando se analisou o número médio de de sovas por caramujo entre $B$. straminea e $B$. tenagophila, observou-se que houve diferença significativamente maior para $B$. straminea. Desta maneira, apesar de não haver diferença significativa no número de ovos por desova entre estas duas espécies, a $B$. straminea mos- 


\section{QUADRO I}

Capacidade ovipositora de Biomphalaria glabrata, Biomphalaria straminea e Biomphalaria tenagophila, em 30 dias de observação, levando-se em conta o número de ovos e desovas.

\begin{tabular}{|c|c|c|c|c|c|c|c|}
\hline Espécie & $\begin{array}{l}\text { no total } \\
\text { de deso- } \\
\text { vas }\end{array}$ & $\begin{array}{l}\text { no médio } \\
\text { de deso- } \\
\text { va/car. }\end{array}$ & $\begin{array}{l}\text { no médio } \\
\text { de deso- } \\
\text { va / car./ } \\
\text { dia }\end{array}$ & $\begin{array}{l}\text { n? total } \\
\text { de ovos }\end{array}$ & $\begin{array}{l}\text { nọ médio } \\
\text { de ovos/ } \\
\text { car. }\end{array}$ & $\begin{array}{l}\text { nQ médio } \\
\text { de ovos/ } \\
\text { car./dia }\end{array}$ & $\begin{array}{l}\text { n: médio } \\
\text { de ovos } \\
\text { desova }\end{array}$ \\
\hline B. glabrata & 493 & 24,65 & 0,82 & 16.314 & 815,7 & 27,19 & 33,09 \\
\hline B. straminea & 481 & 24,05 & 0,8 & 6.611 & 330,55 & 11,01 & 13,74 \\
\hline B. tenagophila & 180 & 9 & 0,3 & 2.049 & 102,45 & 3,41 & 11,38 \\
\hline
\end{tabular}

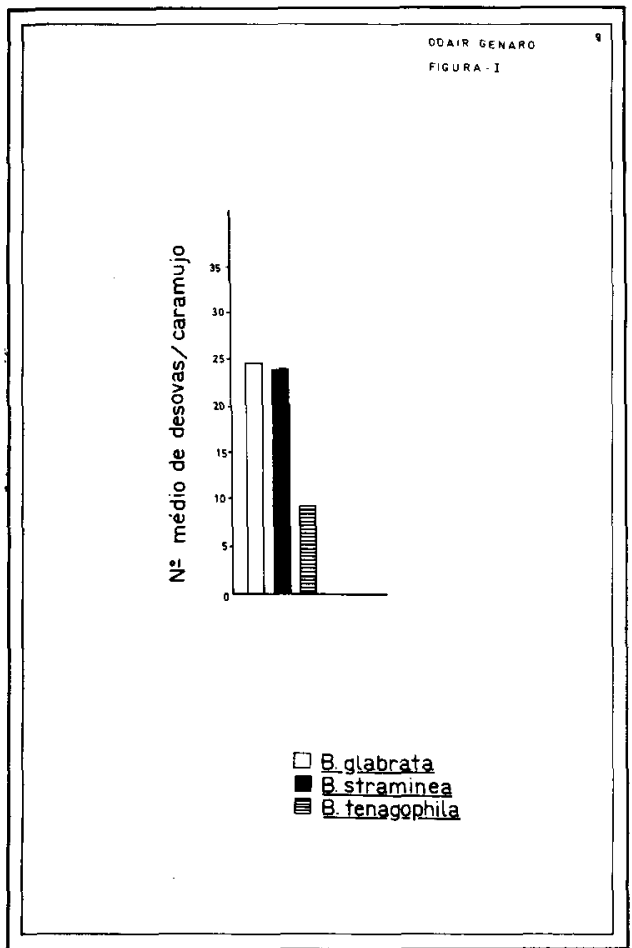

Figura I - Número médio de desovas por caramujo em 30 dias de observação.

trou-se com maior capacidade ovipositora que a B. tenagophila, pelo fato de ter oviposto maior quantidade de cápsulas ovígeras, originando um maior número de ovos.

Entre B. glabrata e $B$. straminea, o número médio de desovas por caramujo foi igual, mas o fato de que o número médio de ovos por desova foi significativamente maior para

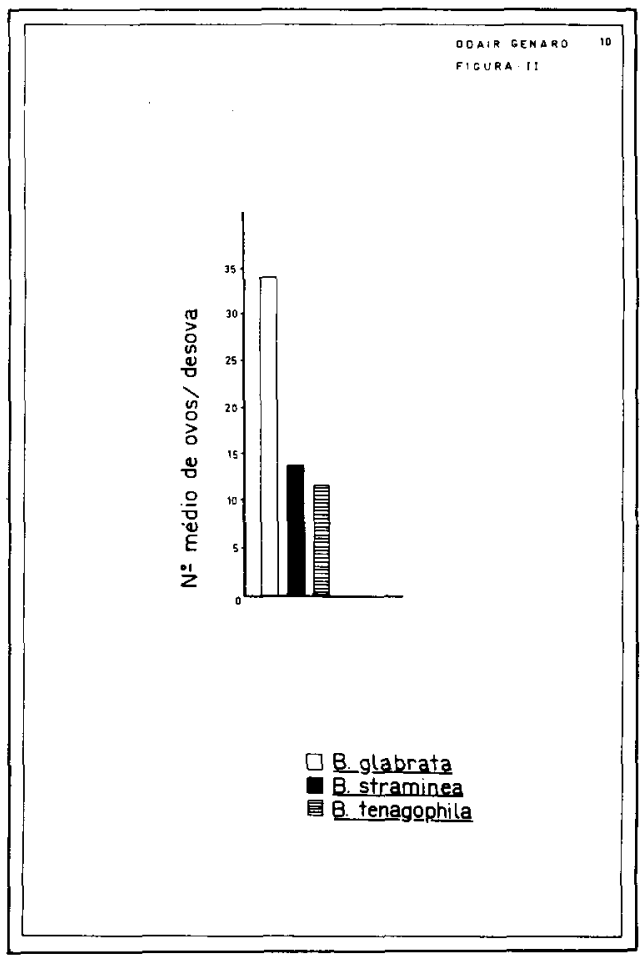

Figura /I - Número medio de ovos por desova em 30 dias de observacão.

B. glabrata, indica que esta espécie tem maior capacidade ovipositora que $B$. straminea.

Assim, os exemplares de B. glabrata apresentaram no experimento maior capacidade ovipositora que as outras duas espécies em questão. A menor capacidade ovipositora observada foi atribuida à espécie B. tenagophila. 


\section{QUADRO II}

Resultados de diferentes autores quanto ao número de ovos por desova de Biomphalaria glabrata, Biomphalaria tenagophila e Biomphalaria straminea.

\begin{tabular}{|c|c|c|c|c|c|c|}
\hline \multirow{2}{*}{ Autor } & \multicolumn{2}{|c|}{ B. glabrata } & \multicolumn{2}{|c|}{ B. tenagophila } & \multicolumn{2}{|c|}{ B. straminea } \\
\hline & $\begin{array}{l}\text { diâmetr } \\
\text { (mm) }\end{array}$ & $\begin{array}{l}\text { ovos/ } \\
\text { desova }\end{array}$ & $\begin{array}{l}\text { diâmetro } \\
(\mathrm{mm})\end{array}$ & $\begin{array}{l}\text { ovos/ } \\
\text { desova }\end{array}$ & $\begin{array}{c}\text { diâmetrc } \\
(\mathrm{mm})\end{array}$ & $\begin{array}{l}\text { o ovos/ } \\
\text { desova }\end{array}$ \\
\hline Chieffi \& cols. (2) & - & 24,15 & - & 27,1 & - & - \\
\hline Jansen (5) & 20 & 45 & - & - & 10 & 12 \\
\hline Kawazoe (6) & 8-11 & 19,9 & 8-11 & 16,2 & - & - \\
\hline Magalhães \& Carvalho (9) & 10 & 21,34 & 10 & 18,20 & - & - \\
\hline Penido \& cols. (11) & - & 24,5 & - & - & - & 13,2 \\
\hline Pimentel (12) & $\begin{array}{l}18,4 \\
1.9,3\end{array}$ & $\begin{array}{l}10,6 \\
28,1\end{array}$ & - & - & - & - \\
\hline Rey (14) & $\begin{array}{l}13 \\
17 \\
24\end{array}$ & $\begin{array}{l}24,5 \\
32,1 \\
52,5\end{array}$ & - & - & - & - \\
\hline Rey (15) & - & $30-60$ & - & - & - & $15-30$ \\
\hline
\end{tabular}

\section{AGRADECIMENTOS}

Ao Dr. Itagiba Geraldo Moretti pela orientação e ao Dr. Aquiles Eugênio Piedrabuena pela análise estatística.

\section{SUMMARY}

The author has studied the reproductive potencial of 3 species of Planorbidae, Biomphalaria glabrata, B. tenagophila and B. straminea from March to April 1978. The data were recorded daily. Eggs-masses of 20 snails of each species were observed. The number of egg-masses and the number of eggs in each were counted. The statistical test showed that the samples of B. glabrata exhibited a larger reproductive potencial than the other species. The smallest reproductive potencial was attribuited to $B$. tenagophila.

\section{REFERENCIAS BIBLIOGRÁFICAS}

1. CHIEFFI, P.P. - Resistência de cêpa de Biomphalaria tenagophila, originária de Londrina (Paraná, Brasil) à infecção por duas cêpas de Schistosoma mansoni. Rev. Soc. Bras. Med. Trop., 9:209-212, 1975.

2. CHIEFFI, P.P., MORETTI, I.G. \& TORNERO, M.T.T. - Potencial reprodutivo, em condições de laboratório, de Biomphalaria glabrata (Say, 1818) e de Biompha. laria tenagophila ( $D^{\prime}$ Orbiny, 1835), originárias do município de Londrina, Estado do Paraná, Brasil, Rev. Inst. Adolfo Lutz, 37:65-70, 1977.

3. COELHO, M.V. - Distribuição geográfica da esquistossomose mansônica. Rev. Bras. Malariol. Doenças Trop., 11:219-246, 1959.

4. COUTINHO, J.G. \& PESSÔA, S.B. Sobre um foco autóctone de esquistossomose mansônica em Jacarezinho (Norte do Paraná), Hospital 35:351-542, 1949.

5, JANSEN, G. - Sobre a validade do Australorbis centimentralis (LUTZ, 1918). Mem. Inst. Oswaldo Cruz, 40:201-209, 1944.

6. KAWAZOE U. - Alguns aspectos da biologia de Biomphalaria glabrata (SAY, 
1818) e Biomphalaria tenagophila (D'ORBIGNY, 1835) (Pulmonata, Planorbidae). II - Fecundidade e Fertilidade. Rev. Saúde Pública São Paulo, 11:47-64, 1977.

7. LIMA, E.C. - Esquistossomose mansoni no Éstado do Paraná. Tese apresentada à Faculdade de Medicina da Univ. do Paraná, Curitiba, 1965.

8. LOBO, A.G.S., LUZ, E. \& CONSOLIN, J. - Novos focos de Esquistossomose mansônica no Estado do Paraná, Rev. Bras. Malariol. Doenças Trop., 6:555-565, 1954.

9. MAGALHÃES, L.A. CARVALHO, J.F. Estudo da postura de duas populações de planorbideos. Rev. Soc. Bras. Med. Trop., 3:245-247, 1969.

10. PELLON, A.B. \& TEIXEIRA, I. - 0 inquérito Helmintológico escolar em cinco Estados das Regiōes Leste-Sul e Centro-Oeste. Publicação da "Divisão de Organização Sanitária", do Ministério da Saúde. Rio de Janeiro, 1953.

11. PENIDO, H.M., PINTO, D.B. \& DESLANDES, N. - Observações sobre as posturas e o tempo de duas espécies de caramujo encontrados no Vale do Rio Doce. Rev. Serv. Esp. Saúde Pública, 4:407.412, 1951.

12. PIMENTEL, D: - Life history of Australorbis glabratus in the intermediate snail host of Schistosoma mansoni in Puerto Rico. Ecology, 38:576-580, 1957.

13. REY, L., AMATO NETO, V. \& SILVA, L.H.P. - Investigação sobre um novo foco de esquistossomose em Uraí (Estado do Paraná). Fol. Cl. et Biol., 20:215-230, 1953.

14. REY, L. - Contribuição para o conhecimento da Morfologia, Biologia e Ecologia dos Planorbideos Brasileiros Transmissores da Esquistossomose. Rio de Janeiro, Servico Nacional de Educação Sanitária. 1956.

15. REY, L. - Condições Gerais de Vida. Rev. Bras. Malariol. Doenças Trop., 9:151-170, 1959.

16. RIBEIRO, S.S., BARANSKI, M.C., CARVALHO, J.D. \& LIMA, E.C. Contribuição ao estudo da esquistossomose no Paraná. Rev. Dep. Saúde Paraná, 3:113-117, 1953. 